EESTI NSV TEADUSTE AKADEEMIA TOIMETISED 1953. II k., nr. I ИЗВЕСТИЯ АКАДЕМИИ НАУК ЭСТОНСКОИ ССР 1953. Том II, N 1

\title{
ГЛАУКОНИТ КАК ЗЕЛЕНЫИ ПИГМЕНТ И ЕГО ПРИМЕНЕНИЕ ДЛЯ СТРОИТЕЛЬНЫХ ПОКРАСОК
}

\author{
Н. К. ПОЛИКАРПОВ, \\ кандидат технических наук
}

Э. К. ЛАНДРА

о. Ю. ПАРДАНЭ

А. э. РитСо

1. Введение

Строительная техника испытывает острый недостаток в прочном и дешевом зеленом пигменте. Применяющаяся до сих пор окись хрома является очень дорогим и остродефицитным материалом, а другие зеленые пигменты - цинковая и свинцовая зелень - нещелочноустойчивы и не могут применяться для известковых фасадных покрасок; поэтому крайне важным являлось найти заменитель окиси хрома, устойчивый по отношению к свету и щелочам.

Эстонским крестьянам было давно известно, что из глауконита может быть приготовлена зеленая малярная краска. Они отбирали куски глауконитовой глины и после выветривания, измельчения и просеивания получали примитивным путем зеленую малярную краску для свонх хозяйственных нужд. Во время первой мировой войны, когда в России ощущался острый недостаток в защитных красках, сотрудниками Комиссии защитных красок при Государственном научно-техническом институте было разработано применение глауконита как защитной краски, и в 1916 году был спроектирован завод по выпуску 1600 кг пигмента в день, но наступившая гражданская война приостановила работы в этой области.

В Советском Союзе в 1927 году подробно исследовались глаукониты Саратовской области, которые по П. П. Пилипенко $\left({ }^{8}\right)$ имеют следующий состав:

$$
21 / 2 \mathrm{R}_{2} \mathrm{O} \cdot \mathrm{RO} \cdot 2 \mathrm{R}_{2} \mathrm{O}_{3} \cdot 8 \mathrm{SiO}_{2} \cdot 4 \mathrm{H}_{2} \mathrm{O}
$$

$\mathrm{R}_{2} \mathrm{O}-\mathrm{Na}_{2} \mathrm{O}$ и $\mathrm{K}_{2} \mathrm{O} ; \mathrm{RO}-\mathrm{CaO}, \mathrm{MgO}$ и $\mathrm{FeO} ; \mathrm{R}_{2} \mathrm{O}_{3}-\mathrm{Al}_{2} \mathrm{O}_{3}$ и $\mathrm{Fe}_{2} \mathrm{O}_{3}$.

A. И. Горбуновым $\left({ }^{6}\right)$ подробно исследовались глаукониты РСФСР, из которых промышленное применение нашел глауконит, добываемый в районе села Лопатина, Московской области, и употребляющийся для изготовления неопермутита.

Ленинградский научно-исследовательский институт Академии коммунального хозяйства имени К. Д. Памфилова производил опыты по получению зеленого пигмента из глауконитовых песков Ленинградской 
области, однако, ввиду малого содержания в глауконитах окислов железа, положительных результатов Институту получить не удалось. Окраска получилась мало интенсивной.

В Эстонии исследования глауконита производились А. Купфером $\left({ }^{2}\right)$ еще в 1877 году, но промышленного использования глауконита в досоветский период не было. После Великой Отечественной войны в Эстонской ССР появились работы по использованию глауконита, выполненные в Институте промышленных проблем (теперь Институт энергетики) АН ЭССР $\left({ }^{2}\right)$ и в Таллинском политехническом институте $\left({ }^{4}\right)$.

\section{2. Местонахождение глауконитовых песков в Эстонской ССР и состав глауконита}

Глауконит принадлежит к осадочным породам морского происхождения, широко распространенным вдоль побережья Финского залива в виде глауконитовых песков, содержащих, кроме глауконита, кварцевый песок, известняк, глину, фосфорит, пирит. Зерна глауконита и кварцевого песка бывают часто сцементированы глиной или мергелем; зерна кварца бывают обычно округленными или овальными, тогда как зерна самого глауконита имеют весьма разнообразную форму.

Подходящими являются такие залежи глауконитовых песков, которые удобны для разработки, содержат значительный процент железа (не менее $16 \% \quad \mathrm{Fe}_{2} \mathrm{O}_{3}$ ) и возможно меньше балласта.

Таким условиям удовлетворяют залежи глауконитовых песков в Маарду и Ласнамяэ (вблизи Таллина).

Нами подробно был исследован находящийся в Маарду слой глауконитового песка толщиной 1,8 метра, залегающий на глубине 6 метров от поверхности земли между слоями известняка и диктионемового сланца.

По окраске и по твердости, в зависимости от глубины залегания, эти залежн были подразделены нами на 5 слоев:

I - глинообразный твердый слой $(0,34$ м) бледнозеленого цвета, содержащий в значительной мере известняк,

II - светлозеленый слой $(0,70$ м), подобный песчанику,

III - рыхлый темнозеленый слой (0,34 м),

IV - светлозеленый слой $(0,20$ м) с отдельными серыми прожилками,

$\mathrm{V}$ - серовато-зеленый слой $(0,18 \mathrm{~m})$.

В местах обнажения первичного слоя глауконита были найдены скопления из мелких частиц глинообразного глауконита. Такие скопления темнозеленого цвета мы обозначаем «MO».

Получаемый из глауконитовых песков очищенный глауконит представляет собой калиевый железо-алюминиевый гидросиликат. Примерный состав эстонского глауконита на основании анализов Я. Ансо и А. Купфера следующий (таблица 1):

$$
\mathrm{R}_{2} \mathrm{O} \cdot 4\left(\mathrm{RO} \cdot \mathrm{R}_{2} \mathrm{O}_{3}\right) \cdot 10 \mathrm{SiO}_{2} \cdot 4 \mathrm{H}_{2} \mathrm{O} \text {, }
$$

где $\mathrm{R}_{2} \mathrm{O}-\mathrm{K}_{2} \mathrm{O}$ и $\mathrm{Na}_{2} \mathrm{O} ; \mathrm{RO}-\mathrm{CaO}, \mathrm{MgO}$ и $\mathrm{FeO} ; \mathrm{R}_{2} \mathrm{O}_{3}-\mathrm{Al}_{2} \mathrm{O}_{3}$ и $\mathrm{Fe}_{2} \mathrm{O}_{3}$.

Удельный вес обогащенного магнитной сепарацией глауконита 2,85-2,95. Содержание водорастворимых солей в обогащенном глауконите $0,6-0,7 \%$. Твердость по шкале Мооса - 3,0-3,5. 


\begin{tabular}{|c|c|c|}
\hline & \multicolumn{2}{|c|}{ Глауконитовый песок } \\
\hline & $\begin{array}{c}\text { из Маарду } \\
\text { (анализ Я. Ансо) } \\
\text { \% }\end{array}$ & $\begin{array}{l}\text { из Палдиски (ана- } \\
\text { лиз А. Купфера) } \\
\%\end{array}$ \\
\hline 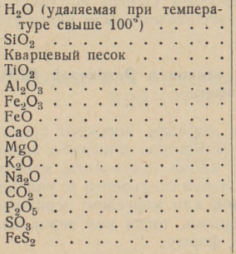 & $\begin{array}{r}3,34 \\
38,31 \\
18,54 \\
0,21 \\
7,34 \\
12,26 \\
3,07 \\
3,30 \\
3,13 \\
6,49 \\
0,20 \\
2,15 \\
0,87 \\
0,22 \\
0,81\end{array}$ & $\begin{array}{r}1,47 \\
3,51 \\
68,53 \\
- \\
2,63 \\
3,44 \\
1,29 \\
2,11 \\
1,55 \\
2,11 \\
0,01 \\
2,10\end{array}$ \\
\hline $\begin{array}{c}\text { влажность и потеря } \\
\text { при прокаливания }\end{array}$ & 100,24 & $\begin{array}{r}100,37 \\
7,40\end{array}$ \\
\hline
\end{tabular}

Потеря веса глауконитом при нагревании в зависимости от температуры показана на рис. 1 .

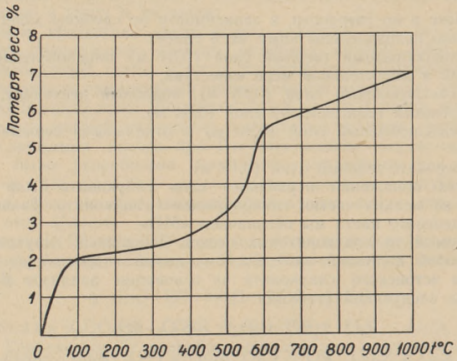

Рис. 1. Потеря веса глауконитом при нагреванин

Анализы проб различных глауконитовых песков Эстонской ССР показали, что интенсивность зеленой окраски глауконита увеличивается по мере повышения содержания железа (табл. 2). 


\begin{tabular}{|c|c|c|}
\hline Глауконитовый песок & Цвет & $\begin{array}{c}\text { Содержание железа } \\
\text { в пересчете на } \\
\% \mathrm{Fe}_{2} \mathrm{O}_{3}\end{array}$ \\
\hline 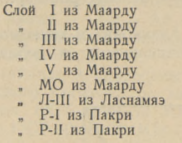 & $\begin{array}{l}\text { Бледнозеленый } \\
\text { Светлозеленый } \\
\text { Темнозеленый } \\
\text { Светлозеленый } \\
\text { Серозеленыи } \\
\text { Темнозеленый } \\
\text { Темнозеленыя } \\
\text { Серыи } \\
\text { Серый }\end{array}$ & $\begin{array}{c}11,0 \\
15,1 \\
20,48 \\
14,14 \\
9,0 \\
19,7 \\
22,5 \\
7,4 \\
4,1\end{array}$ \\
\hline
\end{tabular}

Высокое содержание $\mathrm{Fe}_{2} \mathrm{O}_{3}$ в слоях Маарду III и Ласнамяэ III позволяет получать из них пигмент без удаления балласта. Однако изготовленные таким образом пигменты имеют тусклый цвет, кроме того незначительная толщина этих слоев не позволяет ориентироваться только на них, а приходится брать в разработку, например в Маарду, и менее богатые слои II и IV; в самом руднике организовать отборку балласта (известняка) от глауконитовой породы и последующим раздроблением и сепарацией удалять по возможности всю пустую породу.

Гранулометрический состав глауконитовых песков, полученный посредством ситового анализа, показал, что высушенный и слегка измельченный в ступке глауконитовый песок по мере просеивания через сита с увеличивающимся числом отверстий на $\mathrm{cm}^{2}$ обогащается окислами железа. Тонкие фракции богаче окислами железа, чем крупные, что видно из данных таблицы 3 .

Tаблица 3

\begin{tabular}{|c|c|c|c|c|c|}
\hline \multirow{2}{*}{ Остаток на сите } & \multirow{2}{*}{$\begin{array}{l}\text { Размер } \\
\text { частиц мм }\end{array}$} & \multicolumn{4}{|c|}{$\begin{array}{c}\text { Содержание железа в пересчете на } \\
\mathrm{Fe}_{2} \mathrm{O}_{3} \text { в \% из слоя Маарду }\end{array}$} \\
\hline & & II & III & IV & MO \\
\hline 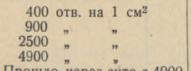 & $\begin{array}{r}\text { до } 0,29 \\
0,18-0.29 \\
0,12-018 \\
0,08-0,12\end{array}$ & $\begin{array}{l}13,5 \\
14,0 \\
15,2 \\
16,0\end{array}$ & $\begin{array}{l}17,0 \\
22,5 \\
22,7 \\
22,9\end{array}$ & $\begin{array}{r}9,5 \\
12,0 \\
15,0 \\
17,4\end{array}$ & $\begin{array}{l}19,0 \\
19,0 \\
19,6 \\
20,0\end{array}$ \\
\hline $\begin{array}{l}\text { Прошло через сито с } 4900 \\
\text { отв. на } 1 \mathrm{~cm}^{2}\end{array}$ & менее 0,08 & 16,7 & 23,3 & 18,8 & 23,3 \\
\hline
\end{tabular}

Более высокое содержание окислов железа-в тонких фракциях является следствием того, что зерна глауконита мягче зерен балласта, и поэтому они легче измельчаются и просеиваются через сита с большим числом отверстий на $1 \mathrm{~cm}^{2}$. Глауконитовые пески из богатых окислами железа слоев Маарду III и Ласнамяэ III можно обогащать после измельчения только одним отсеиванием, например на вибрационных ситах.

\section{3. Физико-химические и механические свойства глауконитового пигмента}

Для получения чистого зеленого пигмента из глауконитовых песков надо выделить глауконит, отделив от него различные примеси (песок, глину, известняк), так как они сильно влияют на качество и цвет пиг- 
мента, делая его тусклым. Освобожденный от таких примесей глауконит дает чистый цвет, устойчивый по отношению к свету, атмосферным влияниям, кислотам и щелочам.

Размер зерен пигмента не должен превышать толщины красочной пленки. У хороших пигментов средний диаметр зерен не больше 30 микрон. Пигмент должен содержать возможно меньше растворимых в воде солей.

Освобожденный от посторонних примесей глауконит в тонкомолотом виде имеет бледнозеленую окраску, не изменяющуюся от добавления

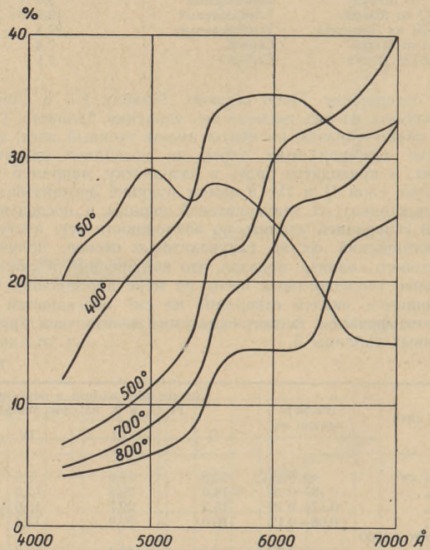

Рнс. 2. Спектрофотометрнческне кривые глауконнтовых пигментов, нагретых до $400-800^{\circ}$, определенные фотометром Пульфрнха.

воды. От добавления масла цвет глауконита меняется от темнозеленого до синезеленого. При нагревании свыше $200^{\circ}$ зеленая окраска природного глауконита переходит последовательно в оливковый, песочный и коричневый цвет. Спектрофотометрические кривые глауконитовых пигментов, нагретых до $400-800^{\circ}$, определенные с помощью фотометра Пульфриха, приведены на рис. 2.

Маслоемкость (то минимальное количество масла, которое требуется для превращения пигмента в краску) $\left(^{3}\right)$ у глауконитового пигмента относительно высокая, а укрывистость - сравнительно низкая, соэтветствующая малой разности в показателях преломления пигмента и масла.

Определение коэффициента преломления глауконита иммерсионным 
методом в поляризационном мнкроскопе показало, что у зеленого глауконитового пигмента $\mathrm{Ng}=1,618$; у коричневого глауконитового пигмента, нагретого до $600^{\circ}, \mathrm{Ng}=1,637$, а у нагретого до $900^{\circ}$ глауконитового пигмента $\mathrm{Ng}=1,640$.

Но так как у масел показатель преломления $\mathrm{Ng}$ около 1,479, то показатель преломления пигмента в масле будет $1,618-1,479=0,139$, что является крайне низким по сравнению с показателями преломления окиси хрома - $\mathrm{Ng}=2,5$ и гематита - $\mathrm{Ng}=2,4\left({ }^{5}\right)$, у которых показатель преломления пигмента в масле будет $2,5-1,479=1,021$ и $2,4-1,479=0,921$.

В таблице 4 приведены данные по определению укрывистости глау конитового пигмента по мере увеличения тонины зерен, проведенному согласно ОСТ-10086-39 МИ-13 и по определению маслоемкости согласно ОСТ-10086-39 МИ-11.

Таблича 4

\begin{tabular}{|c|c|c|c|c|c|}
\hline Пигмевты & $\begin{array}{l}\text { Льняная } \\
\text { олифа в } \\
\% \text { от } \\
\text { граски }\end{array}$ & $\begin{array}{l}\text { Расход } \\
\text { краски } \\
r / \mathbf{M}^{2}\end{array}$ & $\begin{array}{c}\text { Масло- } \\
\text { емкость в } \\
\% \text { олифы } \\
\text { от пиг- } \\
\text { мента }\end{array}$ & $\begin{array}{c}\text { У }_{\text {крыви- }} \\
\text { стость - } \\
\text { расход } \\
\text { пигмента } \\
\text { r/m² }\end{array}$ & $\begin{array}{c}\text { Расход } \\
\text { олифы } \\
\mathrm{r} / \mathrm{M}^{2}\end{array}$ \\
\hline $\begin{array}{l}\text { Oбогащенный глауконитовый пигмент } \\
\text { с } 22,8 \% \text { окислов железа, содержа- } \\
\text { шии: }\end{array}$ & & & & & \\
\hline $\begin{array}{l}\text { a) } 35 \% \text { зерен с диаметром частиц } \\
\text { меньше } 10 \text { микрон и } 64 \% \text { зерен с } \\
\text { диаметром частиц меньше } 60 \text { микрон }\end{array}$ & 50,0 & 266,0 & 100,0 & 133,0 & 133,0 \\
\hline $\begin{array}{l}\text { б) } 45 \% \text { зерен с диаметром частиц } \\
\text { меньше } 10 \text { микрон и } 79 \% \text { зерен с } \\
\text { диаметром частиц меньше } 60 \text { микрон }\end{array}$ & 50,0 & 213,0 & 100,0 & 106,5 & 106,5 \\
\hline $\begin{array}{l}\text { в) } 85 \% \text { зерен с днаметром частиц } \\
\text { меньше } 10 \text { мнкрон и } 99 \% \text { зерен с } \\
\text { днаметром частиц меньше } 60 \text { микрон }\end{array}$ & 49,0 & 178,0 & 95,6 & 91,0 & 87,0 \\
\hline Криворожская охра & 35,7 & 115,0 & 55,4 & 74,0 & 41,0 \\
\hline
\end{tabular}

Глауконитовый пигмент обладает хорошей светоустойчивостью. При испытании пигмента освещением его ртутно-кварцевой лампой ПРК-2 на расстоянии 40 см в течение 350 часов не обнаружено заметного изменения окраски.

Являясь сравнительно мягким материалом, глауконит хорошо размалывается. Щелочная реакция извести не вызывает изменения окраски глауконита и потому он пригоден для известковых фасадных покрытий.

\section{4. Технологический процесс изготовления глауконитового пигмента}

Для получения чистого глауконитового пигмента надо удалить примеси и очищенный продукт подвергнуть помолу до требуемой тонины частиц. Добытый из рудника сырой глауконит часто содержит крупные куски известняка, от которых он дөлжен быть освобожден на месте выемки, после чего сырой глауконит подвергается раздроблению на щековой дробилке до величины зерен 10-15 мм. 
Для удаления из глауконита примесей можно пользоваться различными методами. Ввиду того, что удельный вес глауконита близок $\mathrm{k}$ удельному весу песка, их трудно разделить жидкостями. Отделение глауконита от песка можно произвести отмучиванием, основанным на разделении по размерам частиц. Мелкие частицы, содержащие, как показывает таблица 3 , больше окислов железа, будут отделены от болес крупных частиц; однако в последних будет содержаться слишком много глауконита. Әлектростатический метод сепарации глауконитовых песков связан с известными трудностями. Он действует только при определенной степени влажности сепарируемого материала, причем колеб́ания во влажности допускаются лишь в очень узких пределах. Можно провести сепарацию и методом флотации, но применение его для глауконитовых песков требует еще детального изучения.

Для удаления из глауконита примесей пригодна магнитная сепарация. Глауконит - слабомагнитное вещество, поэтому нужен тип сепаратора с большой магнитной индукцией. Ленточный сепаратор не вполне пригоден, так как глауконит содержит много тонких частиц. При проведении данной работы применялся изготовленный в лаборатории промышленной технологии Института промышленных проблем магнитный сепаратор индукционно-роликового типа, давший удовлетворительные результаты.

При сепарации исходного материала, содержащего 20,8\% окислов железа, из которого были удалены зерна крупностью менее 0,2 мм, прн средней напряженности магнитного поля в сепарирующем воздушном зазоре, равной 14 килогаусс, было получено при первой сепарации $67 \%$ концентрата, при второй сепарации $26 \%$; всего было получено $85 \%$ концентрата с содержанием $23 \%$ окислов железа и $15 \%$ отходов, содержащих $8,3 \%$ окислов железа. Всего было таким образом извлечено железа $94,0 \%$.

В другом случае, при сепарации исходного материала, содержащего $20,8 \%$ окислов железа, $30 \%$ зерен которого были размером не менее 0,2 мм, при той же магнитной нндукции в 14 килогаусс было получено при первой сепарации $66 \%$ концентрата, а при второй - $20 \%$; всего получено $86,0 \%$ концентрата, содержащего $22,8 \%$ окислов железа и $14 \%$ отходов с $8,5 \%$ окислов железа. В этом случае было извлечено железа $94,3 \%$.

Эти опыты показывают, что магнитный сепаратор индукцноннороликового типа работает удовлетворительно и тогда, когда исходный материал содержит до $30 \%$ частиц размером менее 0,2 мм; при содержании же свыше $30 \%$ таких частищ результаты процесса сепарации ухудшаются, поэтому надо стремиться к тому, чтобы в материале, идущем на сепарацию, было бы возможно меньше пылевидных частиц.

Для получения возможно большого выхода концентрата и для правильного проведения магнитной сепарации, требуется: а) чтобы идущий на сепарацию материал был воздушносухим, так как взятый непосредственно из рудника сырой материал плохо сепарируется; б) чтобы исходный материал содержал возможно меньше пылевидных частиц (диаметром менее 0,2 мм); поэтому перед магнитной сепарацией высушенный и грубораздробленный материал надо пропустить через вальцовую мельницу с гладкими валками, дающими мало пылевидных частиц.

Кроме того, сепарация зависит еще от нагрузки сепаратора и скорости вращения ролика. Нагрузка же зависит от подачи материала из бункера. Окружная скорость ролика была в наших опытах $16-24$ м/мин., что является обычной у подобных сепараторов $\left({ }^{7}\right)$. 
Анализ высушенного при $105^{\circ}$ и обогащенного магнитной сепаращией тонкоразмолотого концентрата из слоя Маарду III показал повышение содержания окислов железа с 20,8\% до 23,0\%; уменьшение содержания $\mathrm{CaO}$ и $\mathrm{MgO}$ с $6,4 \%$ до $4,6 \%$ и уменьшение содержания $\mathrm{CO}_{2}$ с $2,1 \%$ до $0,4 \%$ (сравн. с данными таблицы 1$)$.

После магнитной сепарации производится тонкий помол в коннческой мельнище, превращающей обогащенный глауконит в зеленый пиг-

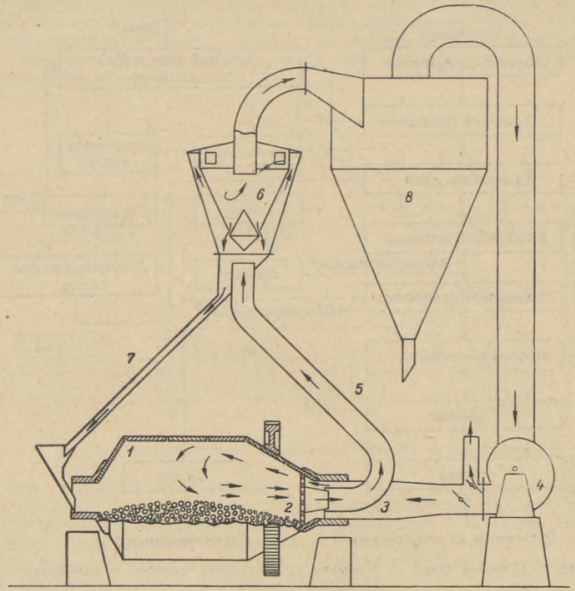

Рис. 3. Коническая мельница с пневматической разтрузкой

мент с диаметром зерен не свыше 60 микрон. Для тонкого помола применяются конические мельницы с длиной цилиндрической части, равной диаметру $\left({ }^{9}\right)$.

Для повышения пронзводительности мельницы надо, чтобы частицы, измельченные до заданных размеров, удалялись немедленно из мельницы. Для этого рекомендуется применять пневматический воздушный транспорт тонкоизмельченных материалов, удаляющий тонкие частицы током воздуха уже во время размола. Но так как током воздуха увлекаются и более крупные частицы, то в воздушном cenараторе необходимо отделить эти крупные частицы от тонких и направить крупные частицы обратно в помольный агрегат. Для этого в лаборатории промышленной технологии была сконструнрована коническая мельница с пневматической разгрузкой (рис. 3). 
В конической мельнице 1 с пневматической разгрузкой расширяется пустотелая цапфа 2, в которую вставляется спещнальное сопло 3 для нагнетания воздуха вентилятором 4. Внутри сопла установлена труба 5 для подачи воздуха со взвешенным в потоке, размолотым материалом из мельницы в сепаратор 6. В сепараторе крупная фракция выделяется из воздушного потока и направляется обратно в мельницу по трубе 7 на домалывание, а тонкая осаждается в циклоне 8. Воздух в циклоне

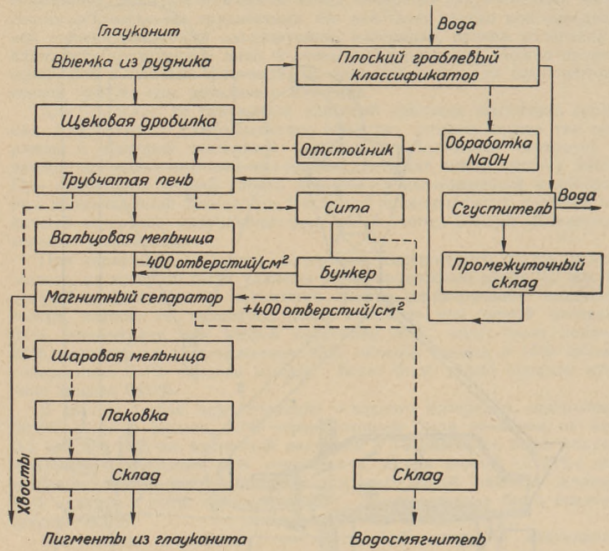

Рис. 4. Основная схема изготовлення из глауконнта пигмента и водосмягчителя

освобождается от измельченного материала и подается вентилятором через сопло в коническую мельницу.

Рассмотрев главнейшие операщии по изготовлению зеленого глауконитового пигмента - магнитную сепарацию и помол в конической мельнице с воздушной сепарацией, можно составить две схемы изготовления пигмента - основную и упрощенную.

Основная схема (рис. 4) включает следующие операции: выемку из рудника, грубое раздробление, сушку, тонкое раздробление, магнитную сепарацию, помол в конической мельнице с воздушной сепарацией. Для грубого раздробления пригодна щековая дробилка, для сушки - вращающаяся трубчатая печь, для тонкого раздробления - вальцовая мельница с гладкими валками.

На этом же рисунке сбоку представлен добавочный вариант, показывающий схему одновременного получения водосмягчителя из глауконита (в таком водосмягчителе ощущается в республике острая потреб- 
ность). Әтот дополнительный варнант состоит в том, что глауконит, предназначенный для изготовления водосмягчителя, после грубого измельчения на щековой дробилке поступает в плоский граблевый классификатор, где он разделяется водой на две фракции: на мелкую, со средним диаметром зерен менее 0,3 мм и крупную - свыше 0,3 мм. Тонкая фракция идет на изготовление пигмента, а крупная фракция обрабатывается раствором едкого натра, затем направляется в отстойники или центрифугу, оттуда в трубчатую печь, затем просеивается через сито с 400 отв. на 1 см² $^{2}$. Остаток на сите со средним диаметром больше 0,3 мм поступает в бункер, затем в магнитный сепаратор и в склад, как водосмягчитель. Прошедшие через сито тонкие частицы идут на изготовление пигмента.

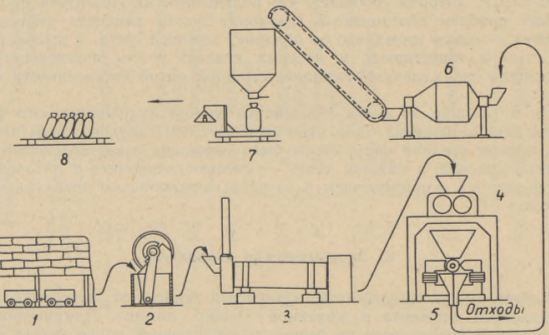

Рис. 5. Упрощенная схема изготовления пигмента из глауконита

При выработке глауконитового пигмента в малых количествах можно значительно упростить схему технологического процесса. На рис. 5 представлена такая упрощенная схема, где 1 - рудник, 2 щековая дробнлка; 3 - сушилка; 4 - вальщы; 5 - магнитный сепаратор, 6 - коническая мельница, 7 - бункер и весы и 8 - склад.

\section{5. Применение глауконитового пигмента}

В строительстве глауконит может быть применен в клеевых и известковых красках и частично в масляных матовых зеленоголубоватых красках. Қлеевая и известковая краски после высыхания почти сохраняют цвет исходного глауконитового пигмента, тогда как масло делает краску темной. В известковых и клеевых красках глауконитовый пигмент обладает отличной свето- и щелочеустойчивостью. Сопротивляемость красок внешним воздействиям зависит главным образом от свойств применяемых связывающих веществ.

Для определения погодоустойчивости были прнготовлены глауконитовые краски, причем в качестве связывающего вещества применялись: льняная олифа, олифа коксоль», синтетическая эфиромасляная олифа, казеиновая эмульсия «ЛОР» (1), жидкое калийное стекло, известь и силикатный цемент. (Данные о составе пробных красок приводятся в конце настоящей работы.) 
Масляные краски были испробованы для покраски по дереву и неощинкованной жести. Краски с другими связывающими веществами (непригодными для покраски по металлу) были испробованы для покраски по дереву, бетону и штукатурке. Испытания на погодоустойчивость были проведены в соответствующем аппарате - «везерометре», сконструированном в Институте промышленных проблем АН ӘССР; в летнее время испытания производились в атмосферных условиях. Оценка состояния проб производилась по установленной ГИПИ-4 десятибалльной системе. Результаты испытаний приведены в таблице 6.

Применкмость глауконитового пигмента для малярных работ была проверена:

1) в Москве, в лаборатории отделочных работ Академии архитектуры СССР, которая сообщает, что полученный от Института промышленных проблем обогащенный глауконит может заменить дефицитный пигмент - окись хрома, что он обладает хорошей свето- и щелочеустойчивостью в известковых и клеевых красках и что интенсивность «красящая сила» глауконнта равняется одной пятой интенсивности окиси хрома;

2) в Таллине, во вновь строющемся здании Художественного фонда стены двух помешений были окрашены зеленым глауконитовым пигментом, причем верхняя часть стены была окрашена в светлозеленый цвет клеевой краской, а нижняя часть - смесью глауконита с литопоном в отношении 1:1, с применением в качестве связывающего вещества олифы «оксоль».

\section{6. Экономические показатели}

Себестоимость глауконитового пигмента зависит от количества вырабатываемого пигмента и желаемой тонины помола. Для вычисления стоимости пигмента взят за основу разработанный ранее проект получення глауконита как водосмягчителя, а также опытные данные о стоимости размола.

При расчете на годовую производительность в 5 тысяч тонн и при механизации добычи и производства глауконита себестоимость тонны готового глауконитового пигмента составит около одной пятидесятой стоимости тонны окиси хрома.

При меньшей годовой производительности и меньшей степени механизации добычи и переработки себестоимость глауконитового пигмента может значительно повысится.

\section{7. Выводы}

1. Из находящихся в Эстонской ССР глауконитовых песков можно приготовить безвредный зеленый пигмент, пригодный для малярных работ.

2. Зеленый-глауконитовый пигмент устойчив по отношению к свету и извести, а потому может быть применен при известковых покрасках фасадов, являясь заменителем до сих пор незаменимой окиси хрома.

3. Зеленый глауконитовый пигмент в качестве компонента клеевой и. масляной красок может найти шнрокое применение для окраски стен во внутренних помещениях, как безвредный пигмент.

4. Технологический процесс изготовления пигмента прост и не требует больших капиталовложений. 


\begin{tabular}{|c|c|c|c|c|c|c|c|c|}
\hline \multicolumn{2}{|c|}{ 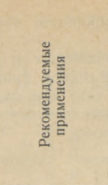 } & 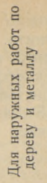 & 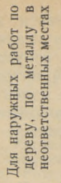 & 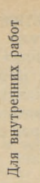 & 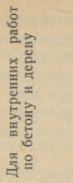 & 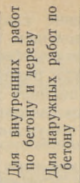 & 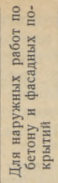 & 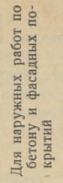 \\
\hline \multicolumn{2}{|c|}{ 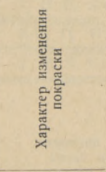 } & 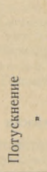 & 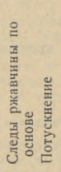 & 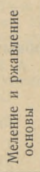 & 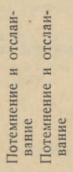 & 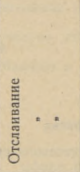 & 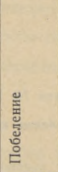 & 莽 \\
\hline \multirow{2}{*}{ 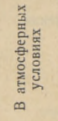 } & 总 & 용 & is is & हे & $+\sigma$ & $+\infty 1$ & 总 & $\infty 1 m$ \\
\hline & 总 & ๖ & $\stackrel{2}{=}$ & $\Xi$ & $R R$ & $\infty$ & $\stackrel{\stackrel{2}{2}}{=}$ & $\stackrel{\cong}{=} \mathrm{I}$ \\
\hline \multirow{2}{*}{ 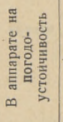 } & 㽰 & 01 & $\approx 0^{\circ}$ & 1 & $\stackrel{\circ}{\circ}$ के & 另路: & in & $10 \infty 0$ \\
\hline & 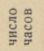 & ₹े। & \& & 1 & ㅇํㄱ \& & 잉ㅇㅇ염 & 8 & ఫ్రి స్సి \\
\hline \multicolumn{2}{|c|}{ 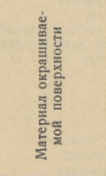 } & 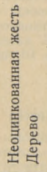 & 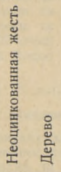 & 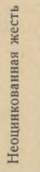 & 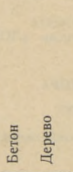 & 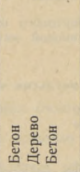 & 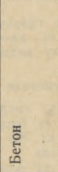 & 密。 \\
\hline \multicolumn{2}{|c|}{ 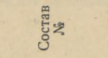 } & - & N & $\infty$ & + & is 0 & - & $\infty$ \\
\hline \multicolumn{2}{|c|}{ 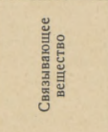 } & 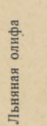 & 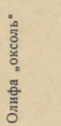 & 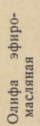 & 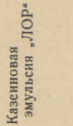 & 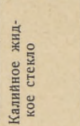 & 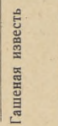 & 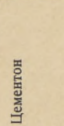 \\
\hline
\end{tabular}


5. Изготовление глауконитового пигмента можно провести комплексно с изготовлением водосмягчителя из глауконита.

6. Интенсивность («красящая сила») глауконита в клеевых и известковых красках равняется одной пятой интенсивности окиси хрома; глауконитовый пигмент дает при окраске более чистый тон, чем окись хрома. 1 тонна окиси хрома может быть заменена 5 тоннами глауконита. Таким образом, глауконит в десять раз дешевле окиси хрома.

Институт энергетики

Академии Наук Эстонской ССР

\section{Составы пробных красок}

Состав № 1

\section{Масляная краска}

1 кг глауконитового пигмента

$1 \mathrm{kГ}$ льняной олифы

$0,2 \mathrm{kг}$ скипидара

Состав № 2

\section{Масляная краска}

$1 \mathrm{kr}$ глауконитового пигмента 1,5 кг олифы коксоль»

Состав № 3

\section{Масляная краска}

1 кг глауконитового пигмента

$1 \mathrm{kг}$ олнфы эфиромасляной

Состав № 4

\section{Казенновая краска}

1 кг глауконитового пигмента

$0,4 \mathrm{kr}$ казенновой эмульсин «ЛОР

$0,8 \mathrm{kr}$ воды

\section{Казеиновая эмульсия єЛОР»}

1,3 кг кислотного казеина

0,33 кr буры

$1,3 \mathrm{Kr} 8 \%$ раствора хозяйственного мыла

$0,52 \mathrm{kr}$ олифы льняной

$0,26 \mathrm{kr}$ кероснна

8 литров воды

\section{Состав № 5}

\section{Силикатная краска}

$1 \mathrm{Kг}$ глауконитового пигмента

$0,25 \mathrm{kr}$ тонкомолотого песка

0,25 кг технического мела

$0,3 \mathrm{K \Gamma}$ талька

2 кг жидкого калийного стекла уд. вес 1,162

Состав № 6

\section{Силикатная краска}

$1 \mathrm{kr}$ глауконитового пигмента

$0,2 \mathrm{kг}$ цинковых белил

0,4 кг талька

$0,8 \mathrm{kг}$ тонкомолотого песка

2,4 кг жндкого калийного стекла уд. вес 1,162

Состав $N 7$

\section{Известковая краска}

1 кг глауконитового пнгмента

1,3 кг силикатного цемента

0,2 кг поваренной соли

$3,0 \mathrm{kr}$ нзвесткового теста, содержаmего $50 \%$ извести, разбавленного водой до 10 литров

\section{Состав № 8}

\section{Цементная краска}

1 кг глауконитового пигмента

$1 \mathrm{kr}$ тонкомолотого песка

0,5 кг силикатного цемента

1,25 кг казенновой эмульсни «ЛОР

1,5 литра воды 


\section{ЛИТЕРАТУРА}

1. Академия Архнтектуры СССР, Справочник архнтектора, т. ХII, Москва, 1946.

2. Ja a n A nso, Glaukonitit kaalisoola allikana, RK „Teaduslik Kirjandus”, 1947.

3. Е. Ф. Беленький и И. В. Ри скин, Химня и технология пигментов, Госхимнздат, 1949 .

4. H. Vilbok, Eesti NSV glaukoniit veepehmendajana, RK „Teaduslik Kirjandus", 1948.

5. А. Н. В.инчелл, Оптнка и микроскопия нскусственных минералов, Госхимтехнздат, Ленинградское отделение, 1933.

6. А. И. Гор бунов, Результаты сравнительного изучения глауконитов разных фацнй, Доклады Академни Наук СССР, т. 70, №5, 1950.

7. В. П. Д е р а ч и М. С. Д а ш ук, Электромагнитные процессы обогащения, Металлургиздат, Свердловск-Москва, 1947.

8. П. П. Пилипенко, Ученые затиски Саратовского государственного университета имени Чернышевского, т. 5, 1927, стр. 255.

9. М. Я. Сапожников и И. А. Булавин, Машины и аппараты силикатной промышленности, Промстройнздат, Москва, 1950. 